\title{
Diallyl Trisulfide Suppresses Oxidative Stress-Induced Activation of Hepatic Stellate Cells through Production of Hydrogen Sulfide
}

\author{
Feng Zhang, ${ }^{1,2,3}$ Huanhuan Jin, ${ }^{1}$ Li Wu, ${ }^{1,2,3}$ Jiangjuan Shao, ${ }^{2,3}$ Xiaojing Zhu, ${ }^{1}$ \\ Anping Chen, ${ }^{4}$ and Shizhong Zheng ${ }^{1,2,3}$ \\ ${ }^{1}$ Jiangsu Key Laboratory for Pharmacology and Safety Evaluation of Chinese Materia Medica, \\ Nanjing University of Chinese Medicine, Nanjing 210023, China \\ ${ }^{2}$ Jiangsu Key Laboratory of Therapeutic Material of Chinese Medicine, Nanjing University of Chinese Medicine, \\ Nanjing 210023, China \\ ${ }^{3}$ State Key Laboratory Cultivation Base for TCM Quality and Efficacy, Nanjing University of Chinese Medicine, \\ Nanjing 210023, China \\ ${ }^{4}$ Department of Pathology, School of Medicine, Saint Louis University, Saint Louis, MO 63104, USA \\ Correspondence should be addressed to Shizhong Zheng; szhengnucm@163.com
}

Received 31 July 2016; Revised 22 December 2016; Accepted 30 January 2017; Published 20 February 2017

Academic Editor: Ranjitsinh Devkar

Copyright (C) 2017 Feng Zhang et al. This is an open access article distributed under the Creative Commons Attribution License, which permits unrestricted use, distribution, and reproduction in any medium, provided the original work is properly cited.

\begin{abstract}
Accumulating data reveal that garlic has beneficial effects against chronic liver disease. We previously reported that diallyl trisulfide (DATS), the primary organosulfur compound in garlic, reduced fibrosis and attenuated oxidative stress in rat fibrotic liver. The present study was aimed at elucidating the underlying mechanisms. The primary rat hepatic stellate cells (HSCs) were cultured and stimulated with hydrogen peroxide $\left(\mathrm{H}_{2} \mathrm{O}_{2}\right)$ for inducing HSC activation under oxidative stress. We examined the effects of DATS on the profibrogenic properties and oxidative stress in $\mathrm{H}_{2} \mathrm{O}_{2}$-treated HSCs. The results showed that DATS suppressed and reduced fibrotic marker expression in HSCs. DATS arrested cell cycle at G2/M checkpoint associated with downregulating cyclin B1 and cyclin-dependent kinase 1, induced caspase-dependent apoptosis, and reduced migration in HSCs. Moreover, intracellular levels of reactive oxygen species and lipid peroxide were decreased by DATS, but intracellular levels of glutathione were increased in HSCs. Furthermore, DATS significantly elevated hydrogen sulfide $\left(\mathrm{H}_{2} \mathrm{~S}\right)$ levels within HSCs, but iodoacetamide (IAM) reduced $\mathrm{H}_{2} \mathrm{~S}$ levels and significantly abrogated DATS production of $\mathrm{H}_{2} \mathrm{~S}$ within HSCs. IAM also abolished all the inhibitory effects of DATS on the profibrogenic properties and oxidative stress in HSCs. Altogether, we demonstrated an $\mathrm{H}_{2} \mathrm{~S}$-associated mechanism underlying DATS inhibition of profibrogenic properties and alleviation of oxidative stress in HSCs. Modulation of $\mathrm{H}_{2} \mathrm{~S}$ production may represent a therapeutic remedy for liver fibrosis.
\end{abstract}

\section{Introduction}

Hepatic fibrosis represents an overactive wound healing process secondary to a variety of chronic liver injuries. During fibrogenesis, excessive connective tissue accumulates in the liver and results in the distortion of hepatic architecture [1]. Chronic liver injury activates and transforms quiescent hepatic stellate cells (HSCs) from vitamin Astoring pericytes to myofibroblast-like cells. Once activated, HSCs become profibrogenic through acquiring proliferative, contractile, and proinflammatory properties as the primary cellular source of extracellular matrix (ECM) components in the liver [2]. Clinical and basic data suggest that oxidative stress critically participates in the progression of fibrosis and acts as mediators of molecular and cellular events implicated in liver fibrosis. Generation of reactive oxygen species (ROS) plays an important role in HSC activation and initiation of hepatic fibrogenesis [3]. Culture of HSCs treated with oxidative stress-related molecules can mimic the HSC activation caused by oxidative stress in liver fibrosis [4]. 
This cellular model is commonly established for investigating the mechanisms of HSC activation and evaluating the effects of antifibrotic candidates. However, currently there are few breakthroughs in the therapeutic intervention of hepatic fibrosis. Identification of antifibrogenic agents that are innocuous is urgently needed.

Garlic has been recognized for prevention and treatment of various diseases by many different cultures throughout history. Recent studies support the effects of garlic and its functional ingredients in a wide range of applications, including anticancer, antithrombotic, antiatherosclerotic, antidiabetic, and antioxidant properties [5]. It is characterized that diallyl trisulfide (DATS), a major organosulfur compound in garlic, is responsible for the pharmacological efficacy of garlic [6]. We previously demonstrated that DATS reduced carbon tetrachloride $\left(\mathrm{CCl}_{4}\right)$-caused liver injury and fibrogenesis in rats, which was associated with inhibition of HSC activation and attenuation of hepatic oxidative stress [7]. However, the molecular mechanisms underlying DATS's antifibrotic activity are not fully understood. Interestingly, emerging data indicate that drugs that target hydrogen sulfide $\left(\mathrm{H}_{2} \mathrm{~S}\right)$ or generate safe levels of $\mathrm{H}_{2} \mathrm{~S}$ in vivo may be therapeutic options for chronic liver diseases [8]. It is given that DATS is an exogenous donor of $\mathrm{H}_{2} \mathrm{~S}$ and the liver has a high hepatic capacity for $\mathrm{H}_{2} \mathrm{~S}$ metabolism [9]. We hypothesized that DATS exerted its antifibrotic effects associated with generation of $\mathrm{H}_{2} \mathrm{~S}$. Experiments were performed to verify this hypothesis.

\section{Materials and Methods}

2.1. Reagents and Antibodies. The following compounds were used in this study: DATS (purity > 97\%; Shenzhen Minn Bolin Biotechnology Co., Ltd., Shenzhen, China), iodoacetamide (IAM; Nanjing Dingguo Changsheng Biotechnology Co., Ltd., Nanjing, China), and mitomycin (Sigma, St Louis, MO, USA). They were dissolved in dimethylsulfoxide (DMSO) for experiments. DMSO at a concentration of $0.02 \%(\mathrm{w} / \mathrm{v})$ was set as a vehicle control throughout the studies. Analytical grade $30 \%$ hydrogen peroxide $\left(\mathrm{H}_{2} \mathrm{O}_{2}\right.$; Sinopharm Chemical Reagent Co., Ltd., Shanghai, China) was diluted with deionized water to indicated concentrations for experiments. The following primary antibodies were used in this study: $\alpha$-SMA, $\alpha 1(\mathrm{I})$ procollagen, and fibronectin (Epitomics, San Francisco, CA, USA); TGF- $\beta$ RI, TGF- $\beta$ RII, PDGF- $\beta$ R, EGF-R, and Bcl-2 (Santa Cruz Biotechnology, Santa Cruz, CA, USA); cyclin A, cyclin B1, CDK1, CDK2, Bax, pro-caspase-9, cleaved-caspase-9, pro-caspase-8, cleavedcaspase-8, pro-caspase-7, cleaved-caspase-7, pro-caspase-3, cleaved-caspase-3, full-length PARP-1, cleaved-PARP-1, and $\beta$-Actin (Cell Signaling Technology, Danvers, MA, USA).

2.2. Cell Culture. Primary rat HSCs were obtained from Jiangyin CHI Scientific, Inc. (Wuxi, China). HSCs were cultured in Dulbecco's modified eagle medium (DMEM; Invitrogen, Grand Island, NY, USA) with $10 \%$ fetal bovine serum (FBS; Wisent Biotechnology Co., Ltd., Nanjing, China), 1\% antibiotics, and grown in a $5 \% \mathrm{CO}_{2}$ humidified atmosphere at $37^{\circ} \mathrm{C}$. Cell morphology was assessed under an inverted microscope (Leica, Germany).
2.3. Cytotoxicity Assay. HSCs were seeded in 24-well plates and cultured for $24 \mathrm{~h}$. HSCs were then treated with DMSO or DATS at indicated concentrations for $24 \mathrm{~h}$. Lactate dehydrogenase (LDH) activity in culture medium was determined using LDH cytotoxicity assay kits (Nanjing Jiancheng Bioengineering Institute, Nanjing, China) according to the protocol. Results were from triplicate experiments.

2.4. Cell Viability Assay. HSCs were seeded in 96-well plates and cultured for $24 \mathrm{~h}$. HSCs were then treated with $\mathrm{H}_{2} \mathrm{O}_{2}$ and/or DATS at indicated concentrations for $24 \mathrm{~h}$. The medium was replaced with $100 \mu \mathrm{L}$ phosphate buffered saline (PBS) containing $0.5 \mathrm{mg} / \mathrm{mL} 3$-(4,5-dimethylthiazol-2yl)-2,5-diphenyl tetrazolium bromide (MTT) and cells were maintained at $37^{\circ} \mathrm{C}$ for $4 \mathrm{~h}$. Then, the crystals were dissolved with $200 \mu \mathrm{L}$ DMSO. The spectrophotometric absorbance was measured with a SPECTRAmax ${ }^{\mathrm{TM}}$ microplate spectrophotometer (Molecular Devices, Sunnyvale, CA, USA) at $490 \mathrm{~nm}$. Results were from triplicate experiments.

2.5. Enzyme-Linked Immunosorbent Assay (ELISA) for $\mathrm{H}_{2} \mathrm{~S}$. HSCs were seeded in 6-well plates and cultured for $24 \mathrm{~h}$. HSCs were then treated with DATS and/or IAM at indicated concentrations for $24 \mathrm{~h}$. Cells were then lysated with RIPA buffer. Intracellular $\mathrm{H}_{2} \mathrm{~S}$ concentrations were determined using an ELISA kit purchased from Nanjing Jiancheng Bioengineering Institute (Nanjing, China) according to the protocol. Experiments were performed in triplicate.

2.6. Cell Cycle Analyses. HSCs were seeded in 6-well plates and cultured for $24 \mathrm{~h}$. HSCs were then treated with various reagents at indicated concentrations for $24 \mathrm{~h}$ and harvested and fixed. Cell cycle was analyzed using cellular DNA flow cytometric kits (Nanjing KeyGen Biotech Co., Ltd., Nanjing, China) according to the protocol. Percentages of cells within cell cycle compartments were determined by flow cytometry (FACSCalibur; BD, Franklin Lakes, NJ, USA). Results were from triplicate experiments.

2.7. Apoptosis Analyses. HSCs were seeded in 6-well plates and cultured for $24 \mathrm{~h}$. HSCs were then treated with various reagents at indicated concentrations for $24 \mathrm{~h}$. Morphology of apoptotic HSCs was evaluated using Hoechst staining kits (Nanjing KeyGen Biotechnology Co., Ltd., Nanjing, China) according to the protocol. Photographs were taken under a fluorescence microscope (Nikon, Tokyo, Japan). In certain experiments, the apoptotic rates were determined by flow cytometry using Annexin V-FITC apoptosis assay kits (Nanjing KeyGen Biotech Co., Ltd., Nanjing, China) according to the protocol. Apoptotic cells were defined as the cells situated in the right two quadrants of each plot and the percentages were determined by flow cytometry (FACSCalibur; BD, Franklin Lakes, NJ, USA). Results were from triplicate experiments.

2.8. Wound Healing Assay. HSCs were seeded in 6-well plates and cultured in DMEM with 10\% FBS. Once the cells attached properly, they were treated with mitomycin at $4 \mu \mathrm{g} / \mathrm{mL}$ for 
$3 \mathrm{~h}$. One linear wound was scraped in each well with a sterile pipette tip, and cells were washed with PBS to remove the unattached cells. Then cells were treated with various reagents at indicated concentrations. Images were taken at $12 \mathrm{~h}$ after wound induction at the same field under an inverted microscope (Leica, Germany). Results were from triplicate experiments.

2.9. Boyden Chamber Assay. HSCs were seeded to the upper wells of polycarbonate membrane transwell inserts $(8 \mu \mathrm{m}$ pore-size; Corning, USA) and cultured in DMEM with $10 \% \mathrm{FBS}$, and meanwhile they were treated with various reagents at indicated concentrations. The lower chambers were filled with complete medium and $\mathrm{H}_{2} \mathrm{O}_{2}$ at $5 \mu \mathrm{M}$. After $12 \mathrm{~h}$ incubation, the polycarbonated filter was removed and the migrated cells on the lower surface were stained with crystal violet. The number of migrated cells at five random fields for each well was counted and normalized to control. Results were from triplicate experiments.

2.10. Measurement of ROS. Analysis of intracellular ROS was determined using dichlorofluorescein diacetate (DCFHDA) probe (Shanghai Genmed Co., Ltd., Shanghai, China). DCFH-DA is an oxidation-sensitive nonfluorescent precursor dye that can be oxidized by $\mathrm{H}_{2} \mathrm{O}_{2}$, other ROS, and low molecule weight peroxides to fluorescent DCFH. HSCs were seeded in 6-well plates and cultured for $24 \mathrm{~h}$. HSCs were then treated with various reagents at indicated concentrations for $24 \mathrm{~h}$. In certain experiments, cells were washed with PBS and incubated with DCFH-DA solutions $(10 \mu \mathrm{M})$ for $20 \mathrm{~min}$. Micrographs were taken under a fluorescence microscope (Nikon, Tokyo, Japan). The excitation and emission wavelengths were set at 488 and $525 \mathrm{~nm}$, respectively. In certain experiments, cells were detached by trypsinization and suspended in DCFH-DA solution $(10 \mu \mathrm{M})$ for $20 \mathrm{~min}$. The intensity of cellular fluorescence intensity was determined by flow cytometry (FACSCalibur; BD, Franklin Lakes, NJ, USA). Results were from triplicate experiments.

2.11. Measurement of Lipid Peroxide (LPO). HSCs were seeded in 6-well plates and cultured for $24 \mathrm{~h}$. HSCs were then treated with various reagents at indicated concentrations for $24 \mathrm{~h}$ and were lysated with RIPA buffer. Intracellular LPO levels were determined using kits purchased from Nanjing Jiancheng Bioengineering Institute (Nanjing, China) according to the protocol. Experiments were performed in triplicate.

2.12. Measurement of Glutathione (GSH). HSCs were seeded in 6-well plates and cultured for $24 \mathrm{~h}$. HSCs were then treated with various reagents at indicated concentrations for $24 \mathrm{~h}$ and were lysated with RIPA buffer. Intracellular GSH levels were determined using kits purchased from Nanjing Jiancheng Bioengineering Institute (Nanjing, China) according to the protocol. Experiments were performed in triplicate.

2.13. Western Blot Analyses. HSCs were treated with various reagents at indicated concentrations for $24 \mathrm{~h}$. Whole cell protein preparation, detection, and band visualization were performed as we previously described [7]. $\beta$-Actin was used as an invariant control for equal loading of total proteins. Representative blots were from three independent experiments.

2.14. Statistical Analyses. Data were presented as mean \pm SD and analyzed using SPSS 16.0 software. Histograms were created using GraphPad Prism 5 software (San Diego, CA, USA). The significance of difference was determined by oneway ANOVA with the post hoc Dunnett's test. Values of $P<$ 0.05 were considered to be statistically significant.

\section{Results}

3.1. DATS Inhibits Viability and Reduces Fibrotic Protein Expression Associated with $\mathrm{H}_{2} \mathrm{~S}$ in HSCs. We initially evaluated potential cytotoxicity of DATS on HSCs using LDH assay, showing that DATS at $20 \mu \mathrm{M}$ or higher concentrations had significant cytotoxic effects on HSCs (Figure 1(a)). We thus investigated DATS effects at nontoxic doses subsequently. We herein used $\mathrm{H}_{2} \mathrm{O}_{2}$ to stimulate HSC activation mimicking oxidative stress, because $\mathrm{H}_{2} \mathrm{O}_{2}$ is the most stable ROS and diffuses readily in and out of cells [10]. DATS at doses of $0.1-10 \mu \mathrm{M}$ inhibited cell viability concentrationdependently in $\mathrm{H}_{2} \mathrm{O}_{2}$-stimulated HSCs (Figure $1(\mathrm{~b})$ ). Moreover, DATS reduced the expression of fibrotic marker proteins $\alpha$-smooth muscle actin ( $\alpha$-SMA), $\alpha 1(\mathrm{I})$ procollagen, and fibronectin and downregulated the type I and II receptors for transforming growth factor- $\beta$ (TGF- $\beta$ RI and TGF$\beta$ RII), platelet-derived growth factor- $\beta$ receptor (PDGF- $\beta \mathrm{R})$, and epidermal growth factor receptor (EGF-R) in $\mathrm{H}_{2} \mathrm{O}_{2}$ stimulated HSCs (Figure 1(c)). We hypothesized that DATS exerted its effects associated with production of $\mathrm{H}_{2} \mathrm{~S}$. The compound IAM has been demonstrated to block both the exofacial and intracellular thiols resulting in elimination of garlic-induced $\mathrm{H}_{2} \mathrm{~S}$ production [11]. Here, IAM at concentration range within $100 \mu \mathrm{M}$ did not cause morphological alterations in HSCs, and accordingly we selected $100 \mu \mathrm{M}$ IAM for subsequent experiments (Figure $1(\mathrm{~d})$ ). We found that DATS concentration-dependently increased the $\mathrm{H}_{2} \mathrm{~S}$ content in HSCs and that IAM at $100 \mu \mathrm{M}$ significantly abrogated DATS elevation of $\mathrm{H}_{2} \mathrm{~S}$ production and reduced the base level of $\mathrm{H}_{2} \mathrm{~S}$ in HSCs (Figure 1(e)), highlighting IAM as a potent blocker of DATS generation of $\mathrm{H}_{2} \mathrm{~S}$. Furthermore, IAM effectively rescued DATS downregulation of fibrotic marker molecules in $\mathrm{H}_{2} \mathrm{O}_{2}$-stimulated HSCs (Figure 1(f)). Taken together, these data suggested that $\mathrm{H}_{2} \mathrm{~S}$ was involved in DATS suppression of the expression of fibrotic proteins in activated HSCs.

3.2. DATS Induces Cell Cycle Arrest Associated with $\mathrm{H}_{2} \mathrm{~S}$ in HSCs. We next examined DATS effects on cell fate of HSCs. DATS arrested cell cycle at G2/M checkpoint in $\mathrm{H}_{2} \mathrm{O}_{2}$ stimulated HSCs (Figure 2(a)). Addition of IAM abrogated DATS-induced G2/M arrest (Figure 2(b)). Cyclin A, cyclin B1, cyclin-dependent kinase (CDK) 1, and CDK2 are four critical regulators at $\mathrm{G} 2 / \mathrm{M}$ checkpoint responsible for driving 


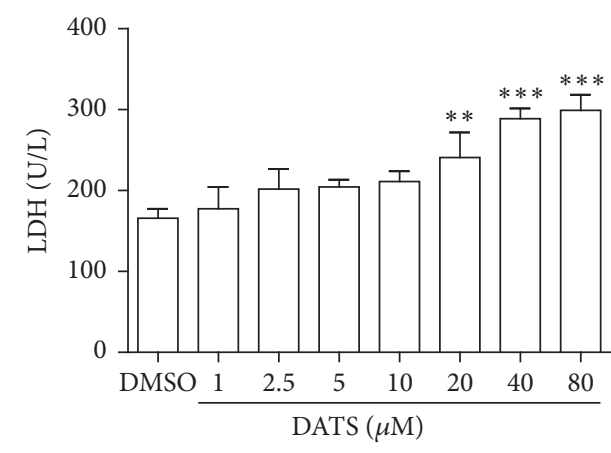

(a)

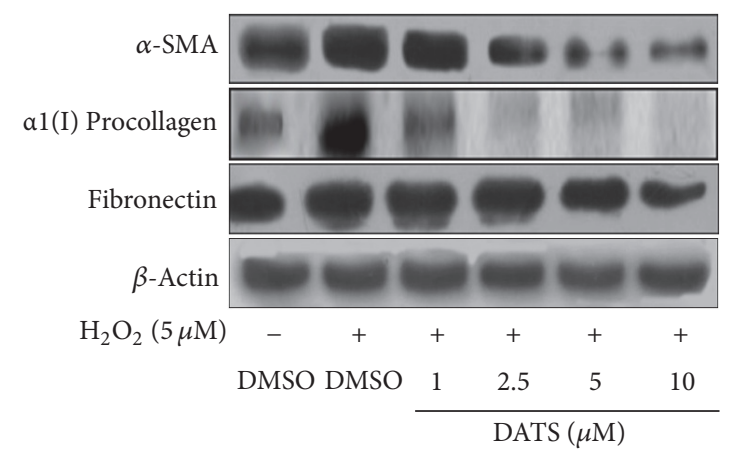

(c)

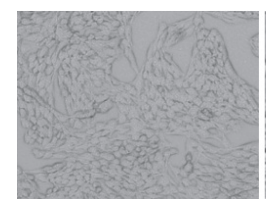

DMSO

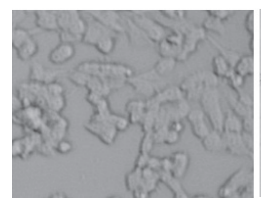

IAM $0.5 \mathrm{mM}$

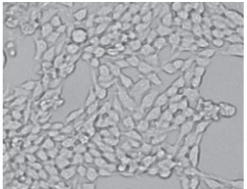

IAM $0.025 \mathrm{mM}$

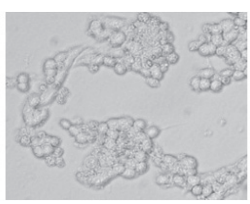

IAM $1 \mathrm{mM}$

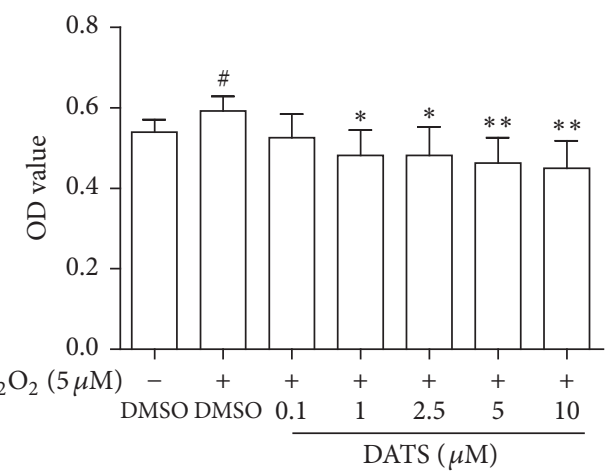

(b)
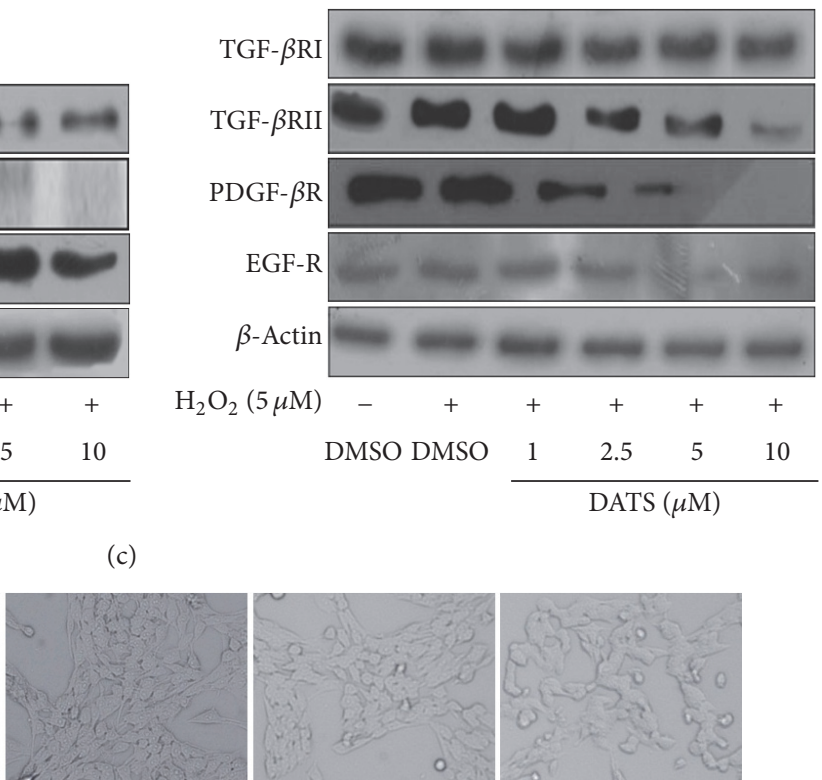

IAM $0.05 \mathrm{mM}$

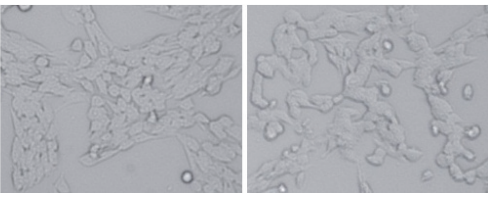

IAM $0.1 \mathrm{mM}$

IAM $0.25 \mathrm{mM}$

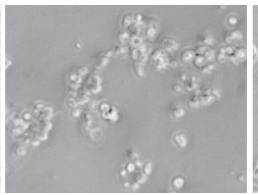

IAM $2.5 \mathrm{mM}$

(d)

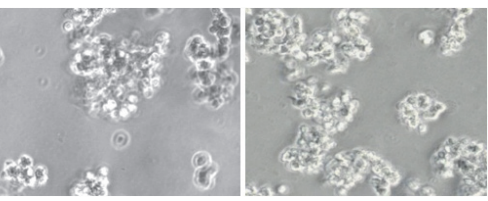

IAM $5 \mathrm{mM}$

IAM $10 \mathrm{mM}$

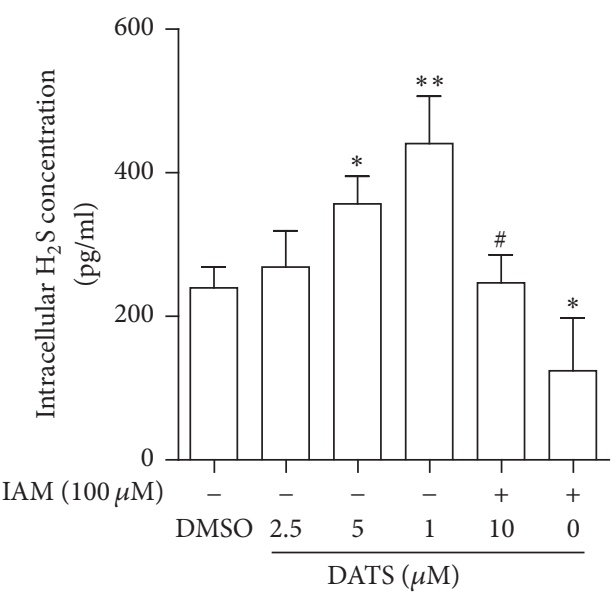

(e)

FIgURE 1: Continued. 

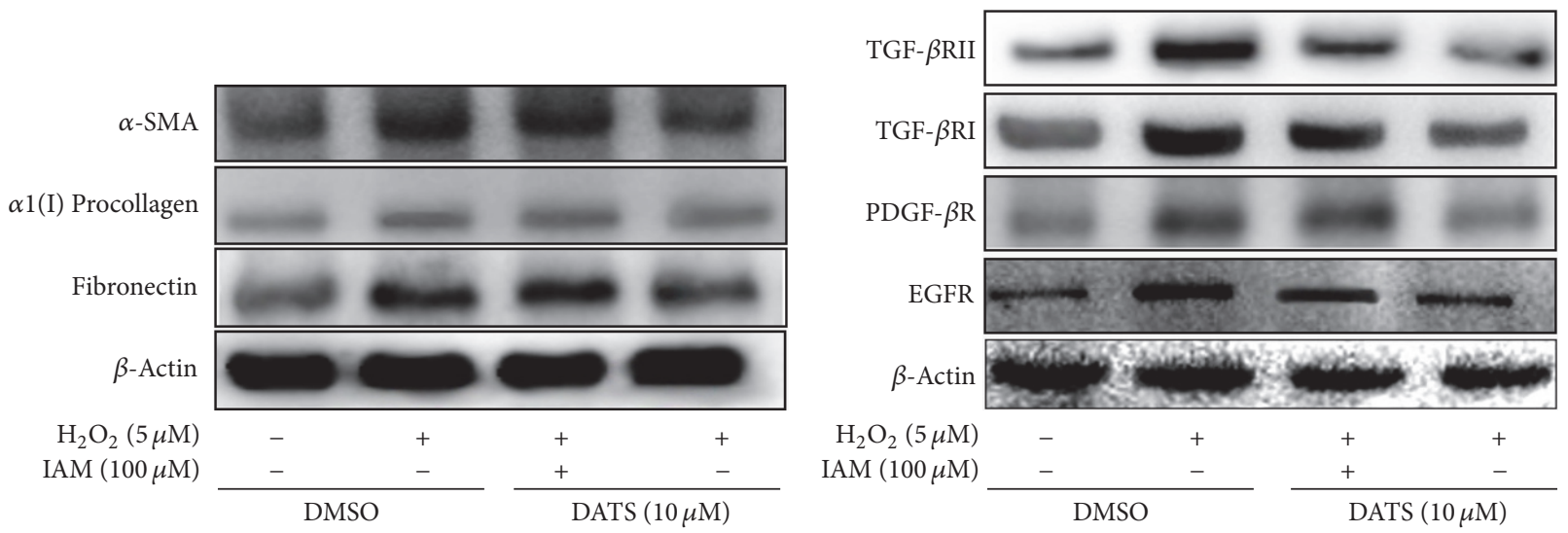

(f)

FIGURE 1: DATS inhibits viability and reduces fibrotic protein expression associated with $\mathrm{H}_{2} \mathrm{~S}$ in HSCs. (a) LDH release assay. Significance: ${ }^{* *} P<0.01$ versus DMSO and ${ }^{* * *} P<0.001$ versus DMSO. (b) MTT assay. Significance: ${ }^{\#} P<0.05$ versus DMSO, ${ }^{*} P<0.05$ versus DMSO + $\mathrm{H}_{2} \mathrm{O}_{2}$, and ${ }^{* *} \mathrm{P}<0.01$ versus DMSO $+\mathrm{H}_{2} \mathrm{O}_{2}$. (c) Western blot analyses of profibrotic marker proteins. (d) Morphology evaluation with light microscope (200x magnification). (e) ELISA for $\mathrm{H}_{2} \mathrm{~S}$ concentration. Significance: ${ }^{*} P<0.05$ versus DMSO, ${ }^{* *} P<0.01$ versus DMSO, and ${ }^{\#} P<0.05$ versus DATS $10 \mu \mathrm{M}$. (f) Western blot analyses of profibrotic marker proteins.

cells into the mitosis process [12]. DATS decreased the expression of cyclin B1 and CDK1, while cyclin A and CDK2 were not apparently affected by DATS (Figure 2(c)). Moreover, DATS inhibition of cyclin B1 and CDK1 was abolished by IAM (Figure 2(d)). These data collectively indicated that $\mathrm{H}_{2} \mathrm{~S}$ was involved in DATS modulation of cell cycle regulators and G2/M checkpoint arrest in HSCs.

3.3. DATS Stimulates Apoptosis Associated with $\mathrm{H}_{2} \mathrm{~S}$ in HSCs. We subsequently examined DATS effects on HSC apoptosis. HSCs treated with DATS exhibited significant DNA condensation and fragmentation with brilliant blue staining (Figure 3(a)), and DATS increased apoptotic rates concentration-dependently in $\mathrm{H}_{2} \mathrm{O}_{2}$-treated HSCs (Figure 3(b)). However, the increase in apoptotic rate by DATS was abolished by IAM (Figure 3(c)). Furthermore, the antiapoptotic protein $\mathrm{Bcl}-2$ was diminished by DATS; the proapoptotic molecule Bax was increased by DATS (Figure 3(d)). DATS also activated the caspase cascade in $\mathrm{H}_{2} \mathrm{O}_{2}$-stimulated HSCs, because the cleaved forms of caspase- 9 , caspase- 8 , caspase- 7 , and caspase-3, and PARP1 were all increased by DATS (Figure 3(d)). However, DATS effects on these molecules were abrogated by IAM (Figure 3(e)). Altogether, these findings indicated that $\mathrm{H}_{2} \mathrm{~S}$ was involved in DATS induction of caspase-mediated apoptosis in HSCs.

3.4. DATS Inhibits Migration Associated with $\mathrm{H}_{2} \mathrm{~S}$ in HSCs. We next examined DATS effects on migration in HSCs. DATS inhibited the lateral migration of $\mathrm{H}_{2} \mathrm{O}_{2}$-activated HSCs (Figure 4(a)). However, IAM abrogated DATS's inhibitory effects on HSC lateral migration (Figure 4(b)). To confirm the results, we performed transwell migration assay to evaluate the vertical migration of HSCs, showing that $\mathrm{H}_{2} \mathrm{O}_{2}$-stimulated vertical migration was suppressed by DATS
(Figure 4(c)). Similarly, DATS effects were also significantly compensated by IAM (Figure 4(d)). Collectively, these data indicated that DATS inhibition of cell migration was associated with $\mathrm{H}_{2} \mathrm{~S}$ in HSCs.

3.5. DATS Alleviates Oxidative Stress Associated with $\mathrm{H}_{2} \mathrm{~S}$ in HSCs. We finally determined DATS effects on oxidative stress in HSCs. Fluorescence microscope analyses and flow cytometry assessments consistently demonstrated that $\mathrm{H}_{2} \mathrm{O}_{2}$-treated HSCs had significantly high intracellular levels of ROS, but DATS decreased ROS production (Figures 5(a) and 5(b)). However, IAM significantly rescued DATScaused reduction in ROS levels in $\mathrm{H}_{2} \mathrm{O}_{2}$-stimulated HSCs (Figure 5(c)). Furthermore, DATS decreased the intracellular levels of LPO and increased the intracellular levels of GSH in $\mathrm{H}_{2} \mathrm{O}_{2}$-stimulated HSCs (Figure 5(d)). However, DATS inhibition of LPO and elevation of GSH were significantly compensated by IAM (Figure 5(e)). Altogether, these results suggested that DATS attenuated oxidative stress in HSCs, which was relevant to $\mathrm{H}_{2} \mathrm{~S}$.

\section{Discussion}

Many studies demonstrated that garlic extracts elicited therapeutic effects against liver fibrosis. Garlic extracts restored liver histology and accelerated ECM degradation, resulting in regression of liver fibrosis in $\mathrm{CCl}_{4}$-intoxicated rats [13]. Administration of aqueous garlic extracts alleviated hepatic oxidative injury and reduced collagen content in bile duct ligation-induced fibrosis in rats [14]. However, these investigations did not identify the specific functional ingredients responsible for the antifibrotic efficacy of garlic. Our previous data showed that DATS attenuated collagen deposition, inhibited HSC activation, and ameliorated oxidative stress in rat fibrotic liver, strengthening the therapeutic value of 


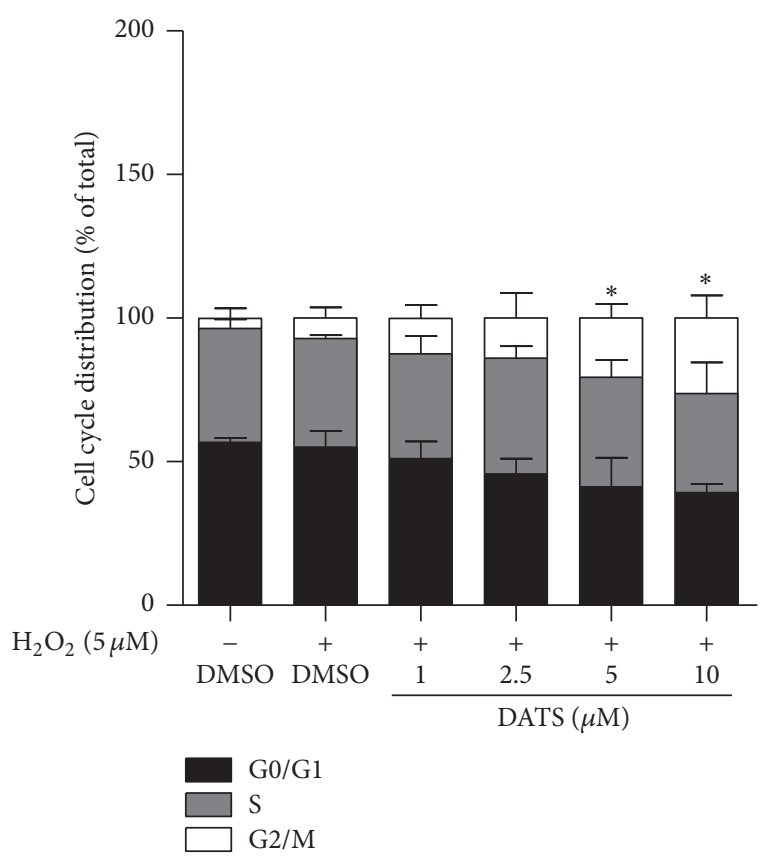

(a)

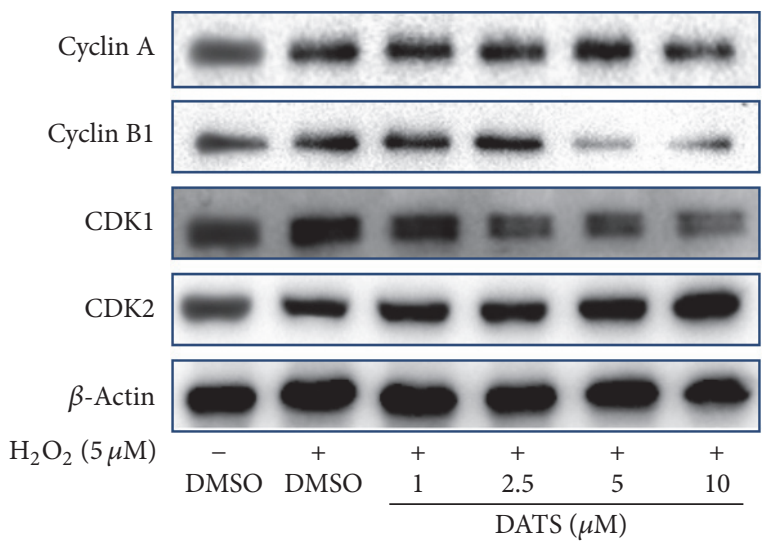

(c)

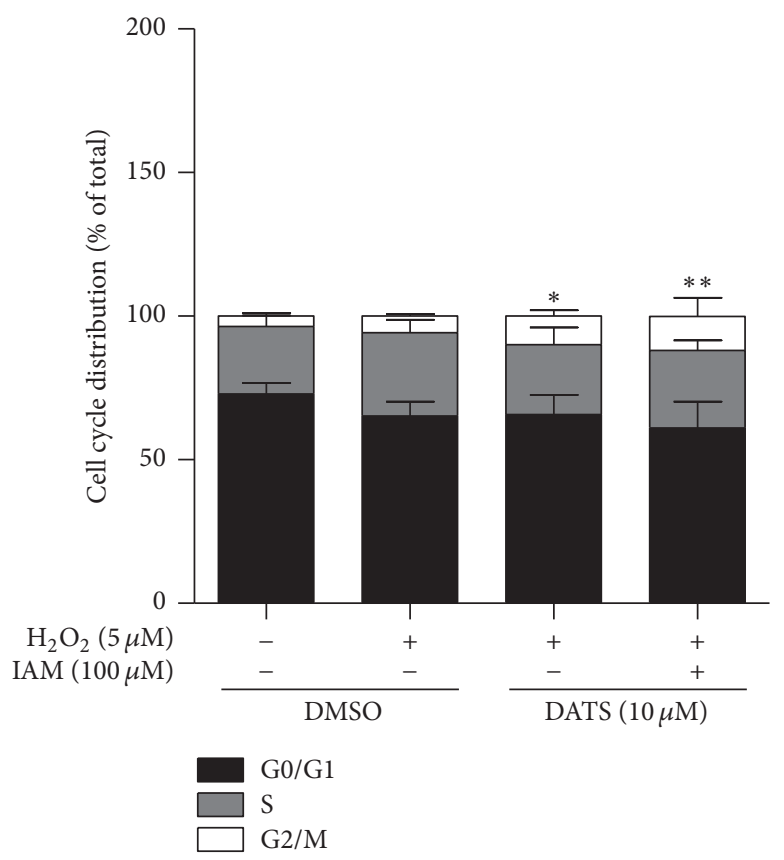

(b)

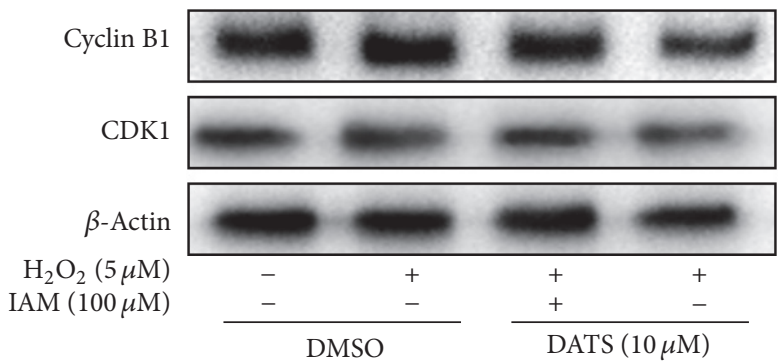

(d)

FIgURE 2: DATS induces cell cycle arrest associated with $\mathrm{H}_{2} \mathrm{~S}$ in HSCs. $(\mathrm{a}, \mathrm{b})$ Percentages of cell cycle distributions were determined by flow cytometry. Significance: ${ }^{*} \mathrm{P}<0.05$ versus DMSO $+\mathrm{H}_{2} \mathrm{O}_{2}$ and ${ }^{* *} \mathrm{P}<0.01$ versus DMSO $+\mathrm{H}_{2} \mathrm{O}_{2}$. (c, d) Western blot analyses of cell cycle regulatory proteins.

garlic for liver fibrosis [7]. Elucidation of the underlying mechanisms would be essentially important for developing DATS as a promising antifibrotic candidate.

Our current experiments could provide consistent support for the prior in vivo data. We found that DATS inhibited HSC activation in culture, which confirmed that HSCs could be target cells for DATS, because DATS was able to inhibit nearly all aspects of HSC activation. To explore the underlying mechanisms, we concentrated on the potential biotransformation of DATS. A 2007 study firstly described the real-time kinetics of $\mathrm{H}_{2} \mathrm{~S}$ production of DATS within cells, showing that DATS with allyl moieties and three sulfur atoms reacted with exofacial membrane thiols and cross the cell membrane to react with GSH to produce $\mathrm{H}_{2} \mathrm{~S}$, which was a thiol-dependent manner for DATS to produce
$\mathrm{H}_{2} \mathrm{~S}$ [11]. Thereafter, increasing evidence reveals that the beneficial effects of garlic-derived organic polysulfides are mediated by production of $\mathrm{H}_{2} \mathrm{~S}$. Herein, we thus strongly speculated that $\mathrm{H}_{2} \mathrm{~S}$ contributed to DATS inhibition of HSC activation. As expected, DATS could significantly increase $\mathrm{H}_{2} \mathrm{~S}$ levels concentration-dependently in HSCs in current study. Moreover, we reasoned that IAM could be a proper blocker of DATS production of $\mathrm{H}_{2} \mathrm{~S}$, because their thioldependent mechanisms of action were exactly matching. Consistently, we here observed that IAM not only abolished DATS elevation of $\mathrm{H}_{2} \mathrm{~S}$ production, but also reduced basal $\mathrm{H}_{2} \mathrm{~S}$ synthesis in HSCs. Accordingly, we used IAM to testify the role of $\mathrm{H}_{2} \mathrm{~S}$ in DATS inhibition of HSC activation properties. The obtained results clearly demonstrated that this $\mathrm{H}_{2} \mathrm{~S}$ manipulation significantly weakened DATS effects. 


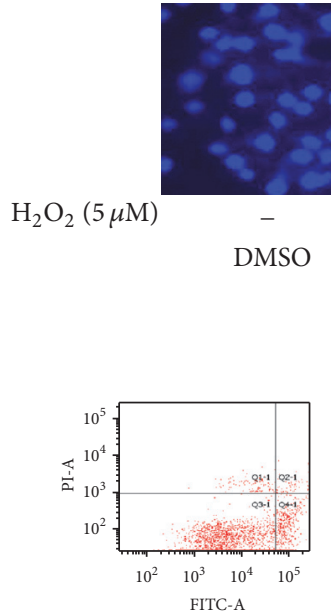

$\mathrm{H}_{2} \mathrm{O}_{2}(5 \mu \mathrm{M})$

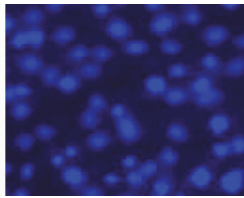

$+$

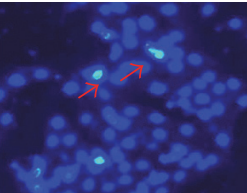

$+$

1

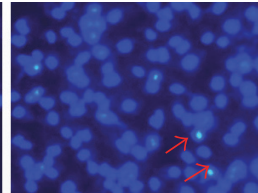

$+$

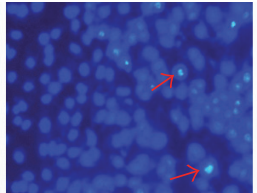

$+$

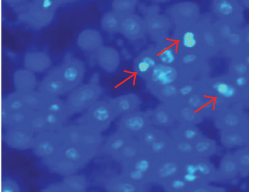

$+$

10

DATS $(\mu \mathrm{M})$

(a)

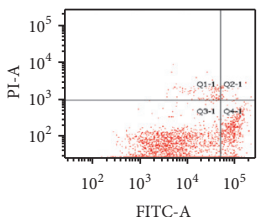

$\stackrel{+}{+}$

DMSO

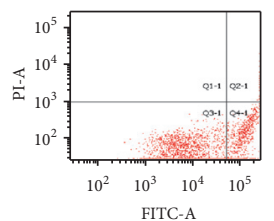

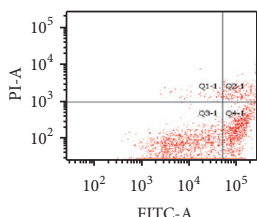

DMSO

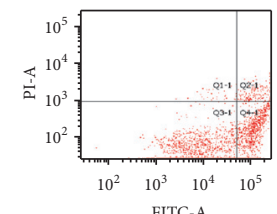

$+$

5

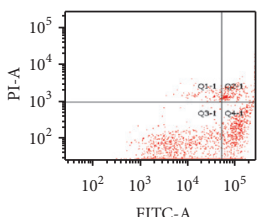

$+$ DATS $(\mu \mathrm{M})$

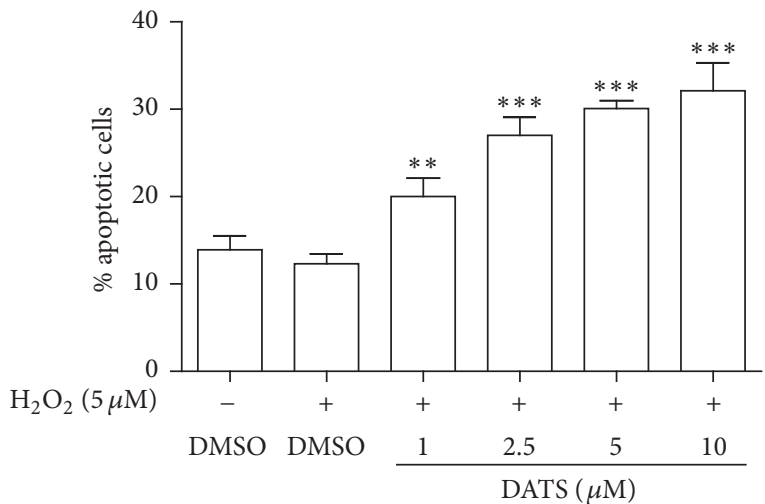

(b)

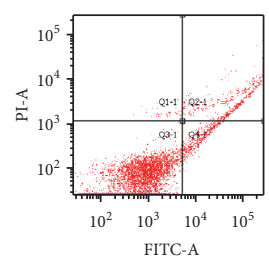

$-$

$-$

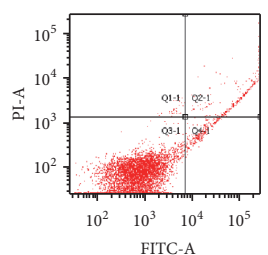
IAM $(100 \mu \mathrm{M})$

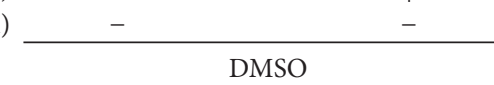

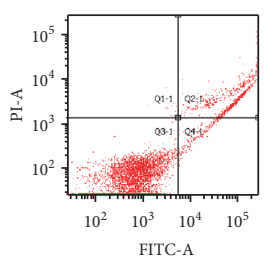
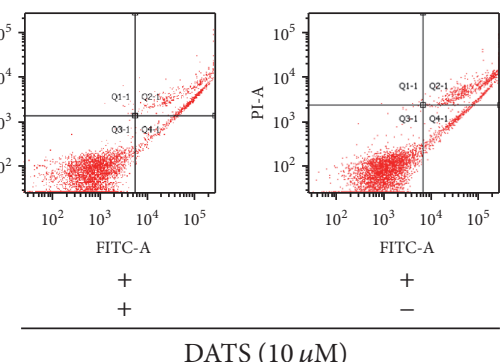

DATS $(10 \mu \mathrm{M})$

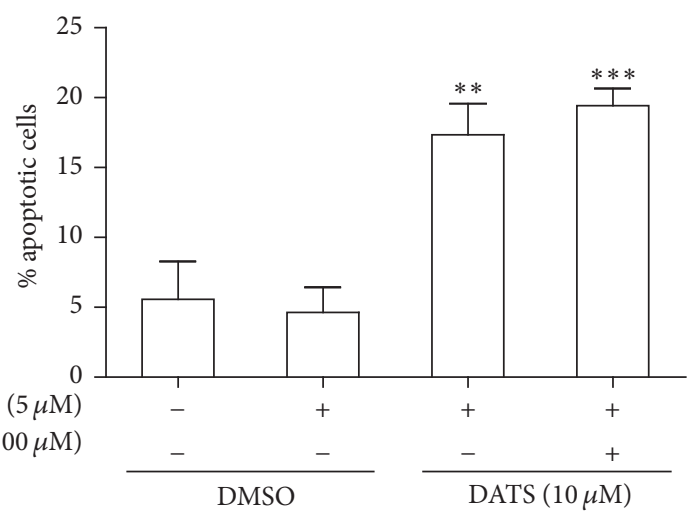

(c)

FIGURE 3: Continued. 

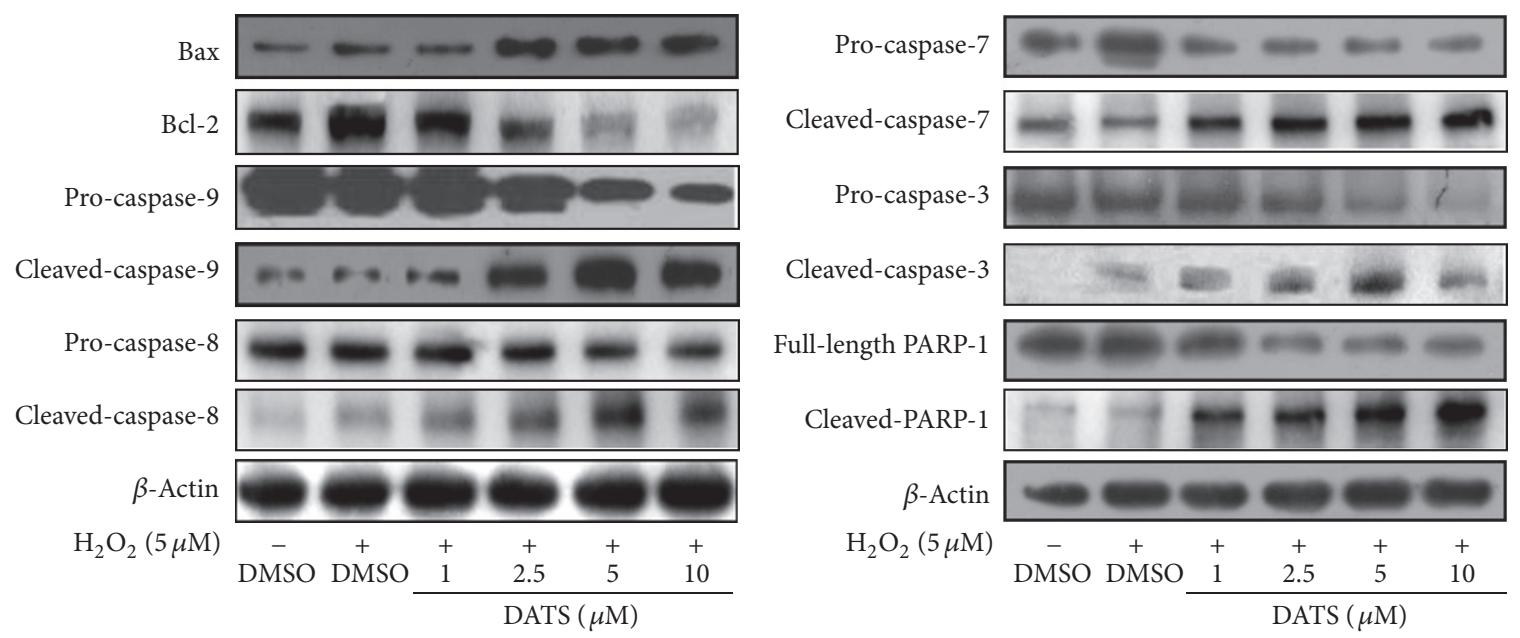

(d)
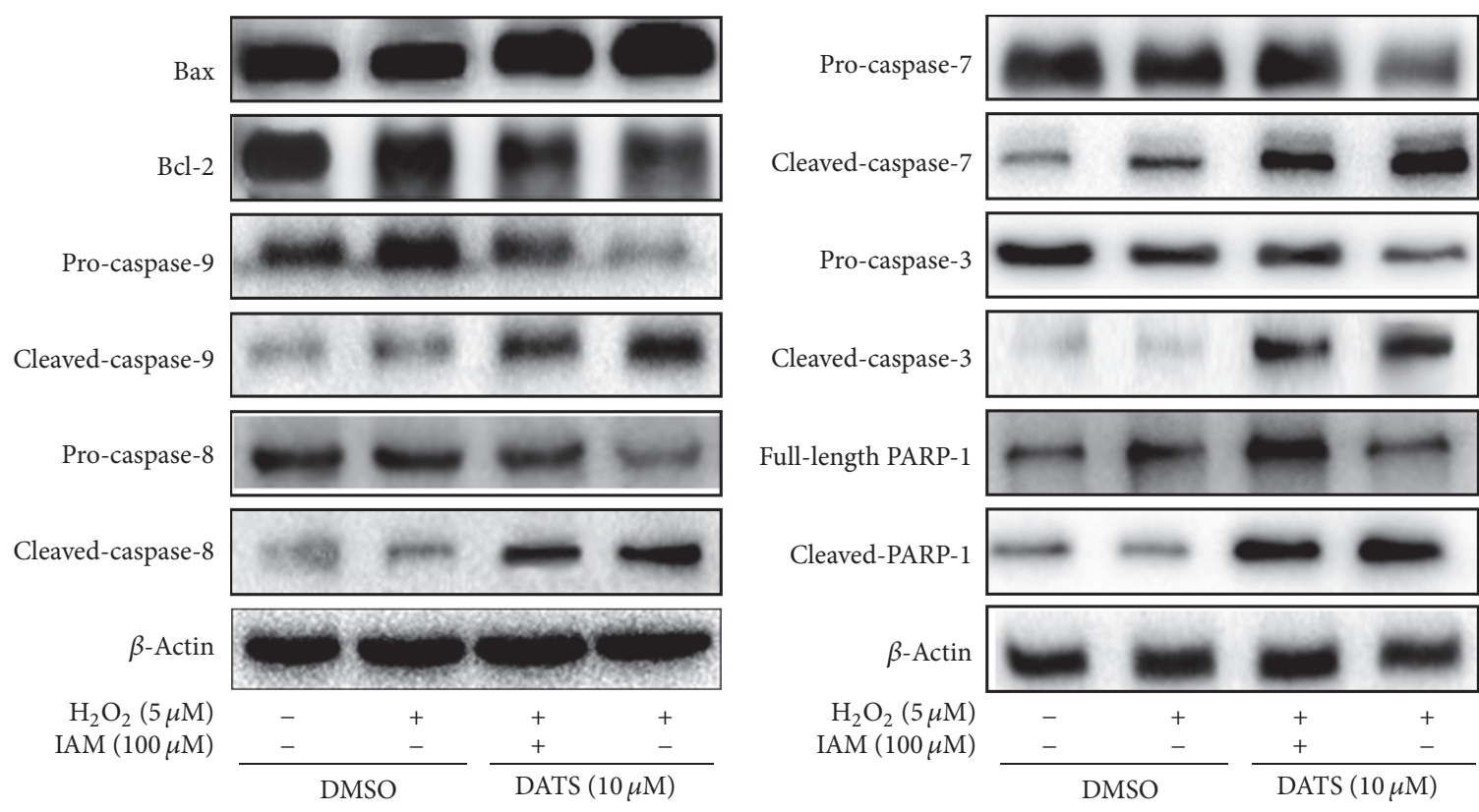

(e)

FIgURE 3: DATS stimulates apoptosis associated with $\mathrm{H}_{2} \mathrm{~S}$ in HSCs. (a) Hoechst fluorescence staining for morphology of apoptotic HSCs under a fluorescence microscope (200x magnification). (b, c) Flow cytometric analyses of apoptotic rates. Significance: ${ }^{* *} P<0.01$ versus DMSO $+\mathrm{H}_{2} \mathrm{O}_{2}$ and ${ }^{* * *} P<0.001$ versus DMSO $+\mathrm{H}_{2} \mathrm{O}_{2}$. (d, e) Western blot analyses of apoptosis regulatory proteins.

We identified the $\mathrm{H}_{2} \mathrm{~S}$ as a molecular link implicated in DATS's antifibrotic activity. Actually, the role of $\mathrm{H}_{2} \mathrm{~S}$ in hepatology has been studied increasingly during recent years. Malfunction of hepatic $\mathrm{H}_{2} \mathrm{~S}$ metabolism may be involved in many chronic liver diseases, including hepatic fibrosis and cirrhosis [15]. Exogenous $\mathrm{H}_{2} \mathrm{~S}$ could reduce hepatotoxicity, liver cirrhosis, and portal hypertension through multiple functions including antioxidation, anti-inflammation, cytoprotection, and antifibrosis [16]. Our current data were consistent with these observations and provided evidence that DATS could be transformed to be $\mathrm{H}_{2} \mathrm{~S}$ that mediated the potent hepatoprotective and antifibrotic effects in HSCs.

We demonstrated that $\mathrm{H}_{2} \mathrm{~S}$ was involved in DATS effects on many aspects of HSC activation, including fibrotic marker expression, cell cycle, apoptosis, migration, and the status of oxidative stress. Consistent with our data, recent investigations showed that sodium hydrosulfide, a well-known inorganic $\mathrm{H}_{2} \mathrm{~S}$-releasing molecule, suppressed proliferation and induced G1 phase cell cycle arrest in HSCs [17] and attenuated collagen expression in rats with $\mathrm{CCl}_{4}$-induced hepatic fibrosis [18]. These findings collectively suggested $\mathrm{H}_{2} \mathrm{~S}$ as a signaling molecule regulating the pathophysiology of HSCs. Actually, $\mathrm{H}_{2} \mathrm{~S}$ promotes a number of cellular signals that regulate metabolism, proliferation, and apoptosis in various types of cells. For example, exogenous treatment with $\mathrm{H}_{2} \mathrm{~S}$ led to growth inhibition with cyclin D1 downregulation in rat smooth muscle cells [19] and stimulated apoptosis by downregulation of $\mathrm{Bcl}-2$ and $\mathrm{Bcl}-\mathrm{xL}$ in portal vein smooth 


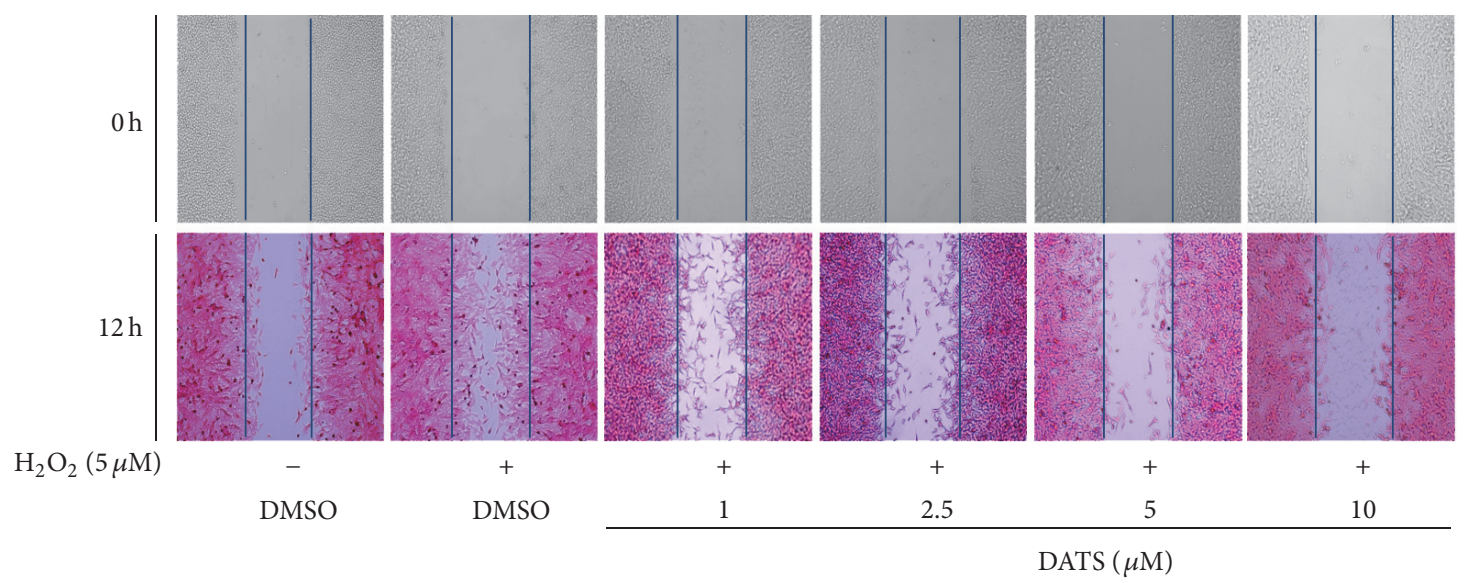

(a)

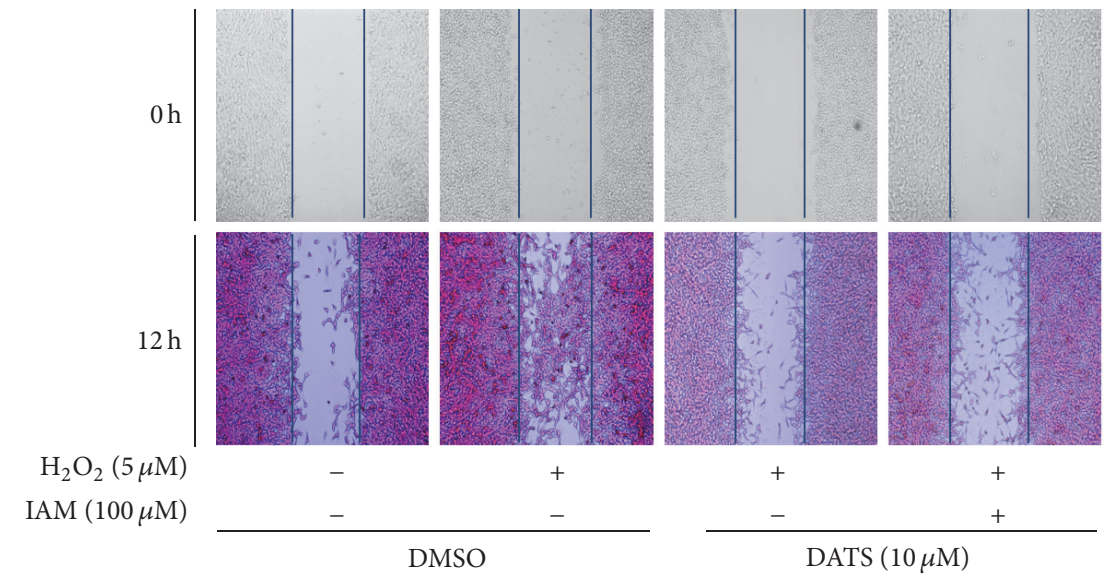

(b)
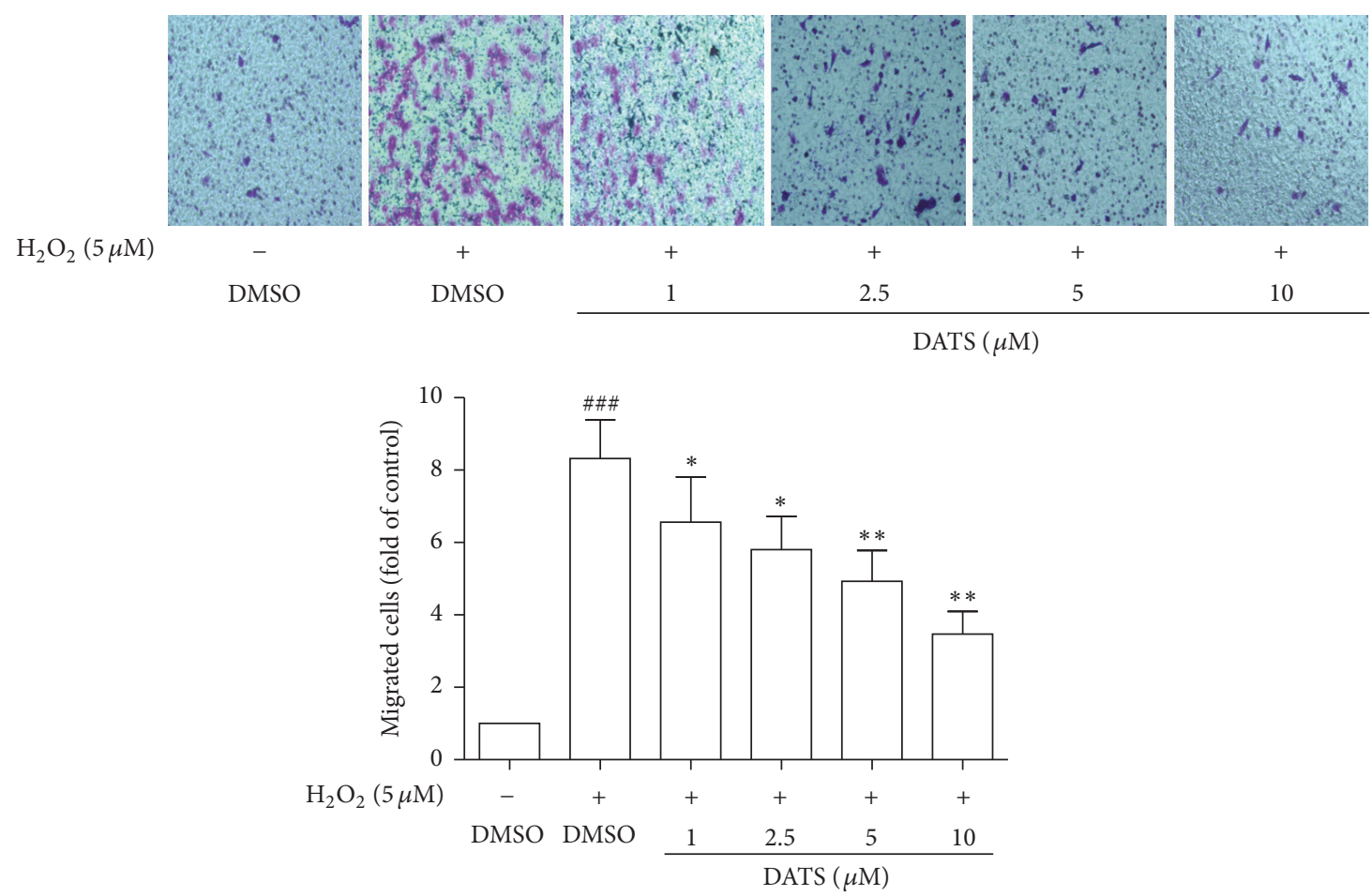

(c)

FIGURE 4: Continued. 

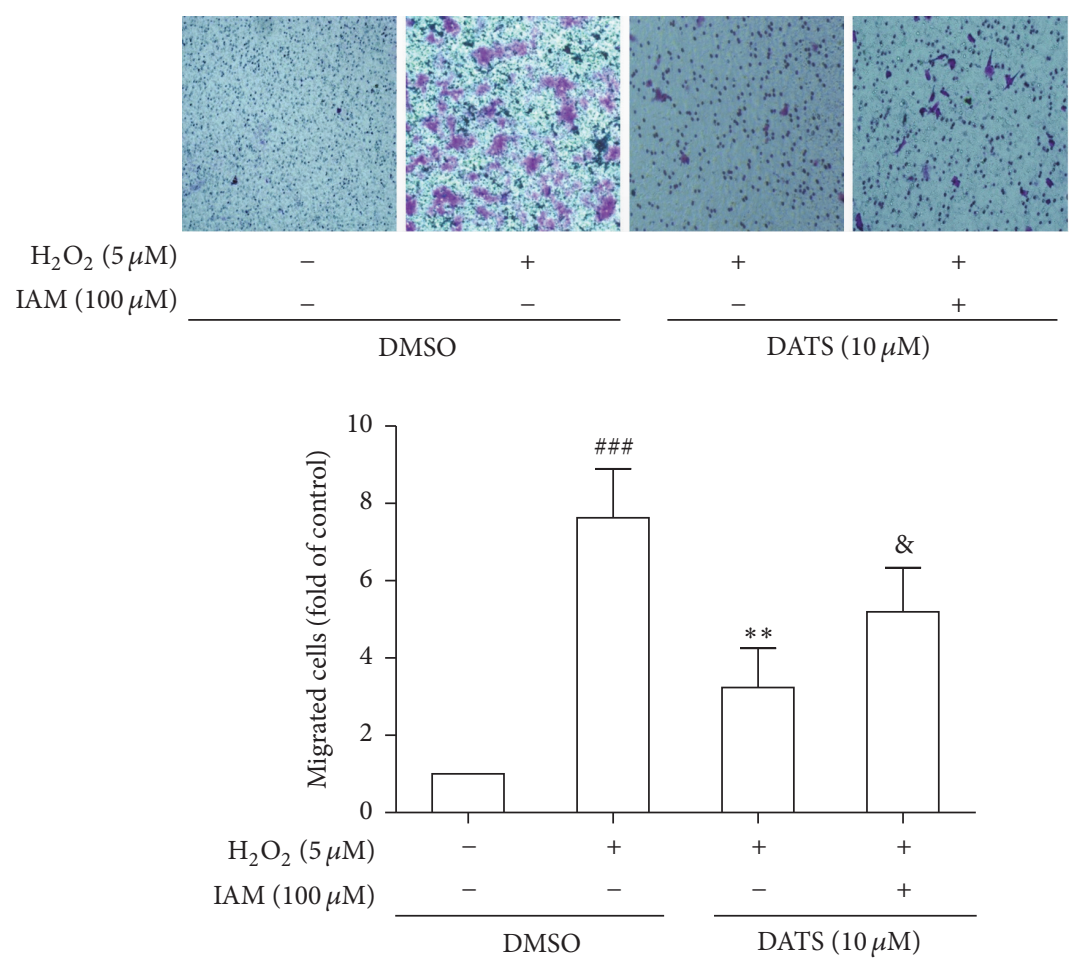

(d)

Figure 4: DATS inhibits migration associated with $\mathrm{H}_{2} \mathrm{~S}$ in HSCs. $(\mathrm{a}, \mathrm{b})$ Wound healing assay (50x magnification). (c, d) Boyden chamber assay (50x magnification). Significance: ${ }^{\# \# \#} \mathrm{P}<0.001$ versus DMSO, ${ }^{*} P<0.05$ versus DMSO $+\mathrm{H}_{2} \mathrm{O}_{2},{ }^{* *} P<0.01$ versus DMSO $+\mathrm{H}_{2} \mathrm{O}_{2}$, and ${ }^{\&} \mathrm{P}<0.05$ versus DATS $+\mathrm{H}_{2} \mathrm{O}_{2}$.

muscle cells [20]. These observations were recaptured in HSCs by our present study and potentiated the role of $\mathrm{H}_{2} \mathrm{~S}$ as a gaseous signaling molecule with a DNA damaging function. Interestingly, there was evidence that administration of sodium hydrosulfide significantly inhibited hepatocyte apoptosis in hepatic ischemia reperfusion-induced injury in rats, suggesting a hepatoprotective role for $\mathrm{H}_{2} \mathrm{~S}$ in vivo [21]. However, it should be noted that this study examined apoptosis molecules in whole liver tissues rather than in single type of cells. This may raise a possibility that the proapoptotic effects of $\mathrm{H}_{2} \mathrm{~S}$ on HSCs could be masked due to the overwhelming amount of hepatocytes in the liver. It could also be assumed that the different effects of $\mathrm{H}_{2} \mathrm{~S}$ on apoptosis were cell-specific and disease-specific. Furthermore, we found that DATS inhibited HSC migration associated with $\mathrm{H}_{2} \mathrm{~S}$. Consistently, recent studies showed that DATS suppressed migration and invasion in human colon cancer cells [22] and breast cancer cells [23]. Another important issue is that increasing evidence elucidates the fundamental role of HSC in liver immunology, because HSCs represents a versatile source of many soluble immunological active factors and may act as an antigen presenting cell [24]. Understanding the role of HSCs as central regulators of liver immunology may lead to novel therapeutic strategies for chronic liver diseases. Interestingly, $\mathrm{H}_{2} \mathrm{~S}$ has multiple and complex cellular signaling roles in relation to immunological modulation under certain pathophysiological conditions [25]. However, studies addressing how $\mathrm{H}_{2} \mathrm{~S}$ regulates $\mathrm{HSC}$ immunology during hepatic fibrosis are not seen, which could be an attractive field in hepatology.

We herein evaluated DATS effects in an oxidative stressinduced HSC activation model, because signs of oxidative stress are concomitant or precede HSC activation and collagen deposition [3]. We also suggested a role for $\mathrm{H}_{2} \mathrm{~S}$ in regulation of oxidative stress in HSCs. $\mathrm{H}_{2} \mathrm{~S}$ could increase intracellular GSH concentrations and suppress oxidative stress in mitochondria [26]. $\mathrm{H}_{2} \mathrm{~S}$ could also protect murine liver against ischemia reperfusion injury through upregulation of intracellular antioxidant pathways [27]. The antioxidant effects of $\mathrm{H}_{2} \mathrm{~S}$ have recently been examined through use of $\mathrm{H}_{2}$ S-releasing derivative ACS67, which was found to inhibit ROS formation and NADH oxidation in endothelial cells [28]. In current study, $\mathrm{H}_{2} \mathrm{~S}$ also contributed to DATS attenuation of oxidative stress in HSCs. However, whether $\mathrm{H}_{2} \mathrm{~S}$ exerted its antioxidant effects by virtue of its undoubted reducing activity or by its activation of endogenous defense systems merits further investigation. Furthermore, it is necessary to use an additional HSC line and another blocker of $\mathrm{H}_{2} \mathrm{~S}$ generation to make the results more credible. There is also a need to carry out in vivo studies using certain $\mathrm{H}_{2} \mathrm{~S}$ generation blocker to validate the $\mathrm{H}_{2} \mathrm{~S}$-dependent mechanism underlying the antifibrotic effects of DATS, which is ongoing in our laboratory.

In summary, DATS inhibited the profibrogenic properties and alleviated oxidative stress in HSCs. These effects were 


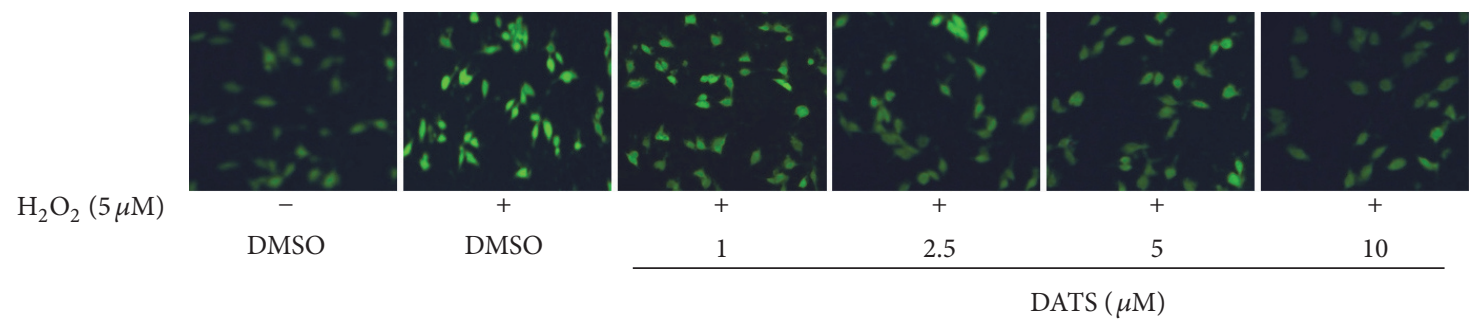

(a)
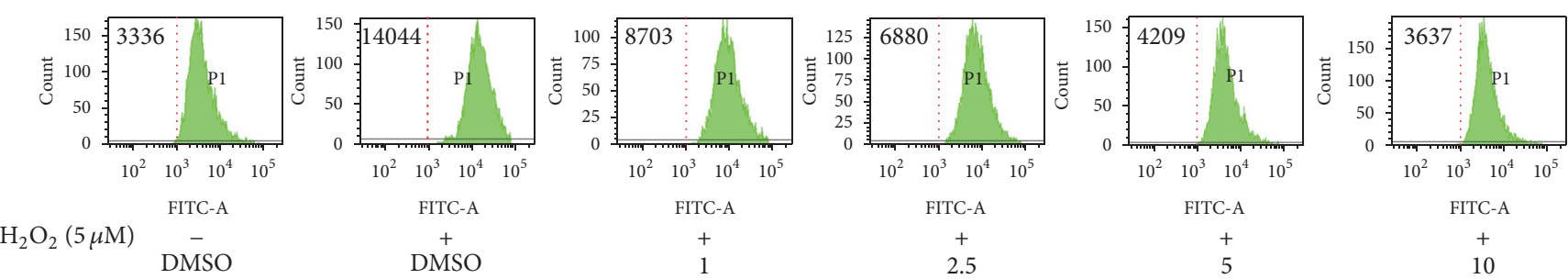

DMSO

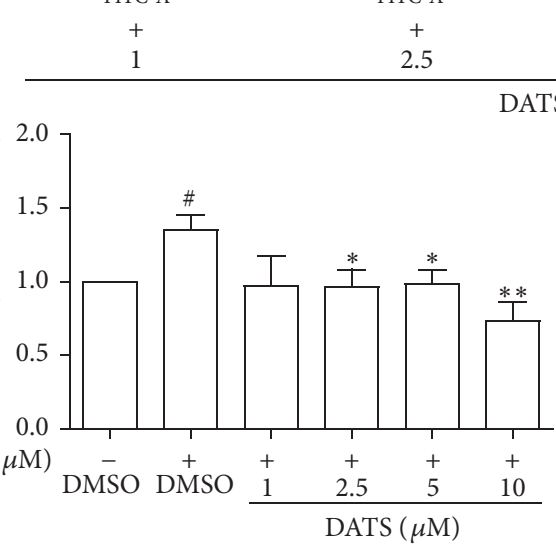

(b)
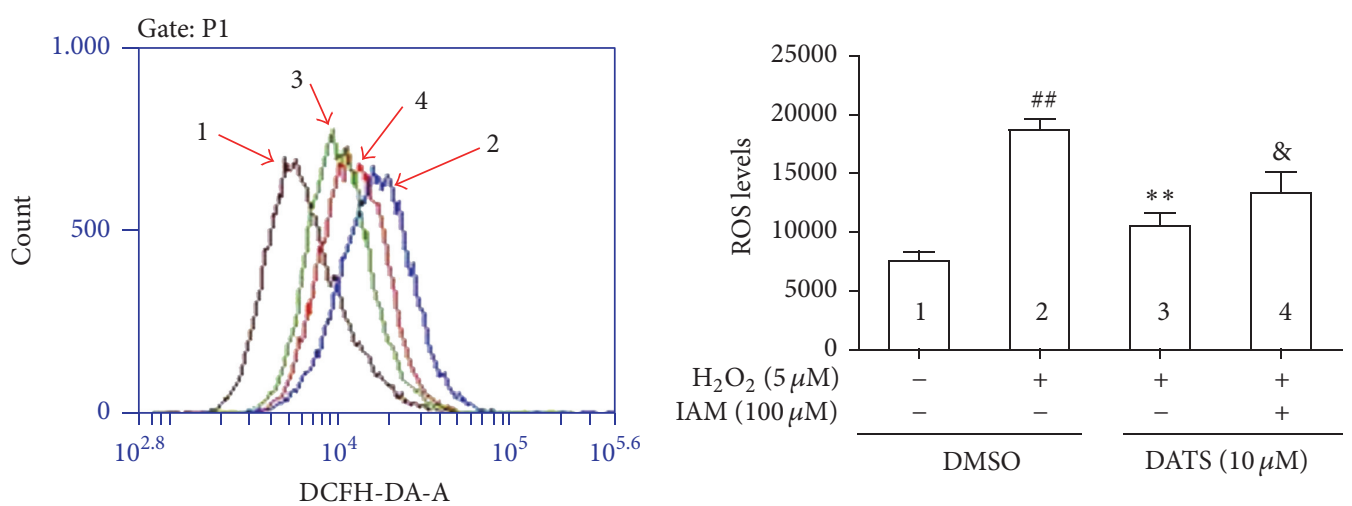

(c)
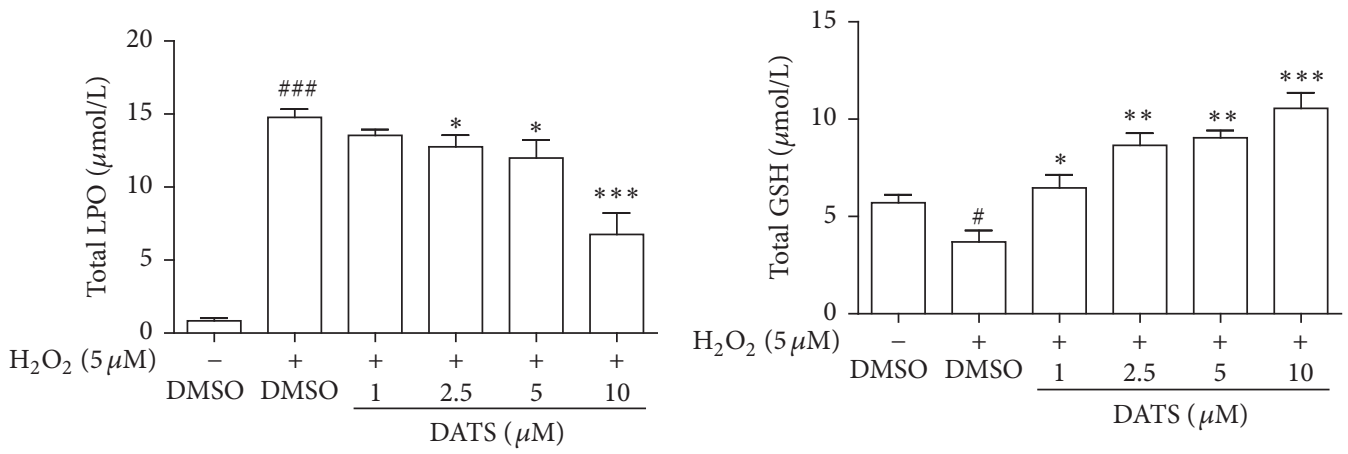

(d)

FIGURE 5: Continued. 

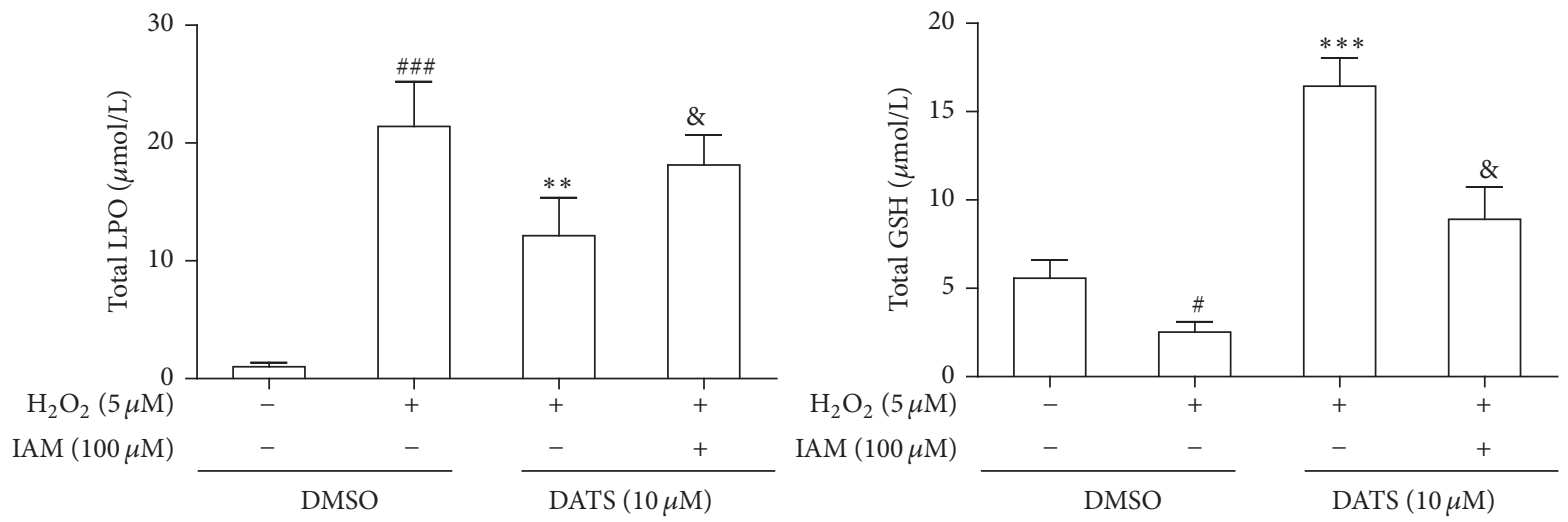

(e)

FIGURE 5: DATS alleviates oxidative stress associated with $\mathrm{H}_{2} \mathrm{~S}$ in HSCs. (a) Analyses of intracellular ROS using a fluorescence microscope (100x magnification). (b, c) Analyses of intracellular ROS using flow cytometry with quantification. Significance: ${ }^{\#} P<0.05$ versus DMSO, ${ }^{\# \#} \mathrm{P}<0.01$ versus DMSO, ${ }^{*} \mathrm{P}<0.05$ versus DMSO $+\mathrm{H}_{2} \mathrm{O}_{2},{ }^{* *} \mathrm{P}<0.01$ versus DMSO $+\mathrm{H}_{2} \mathrm{O}_{2}$, and ${ }^{\&} \mathrm{P}<0.05$ versus DATS $+\mathrm{H}_{2} \mathrm{O}_{2}$. (d, e) Analyses of intracellular LPO and GSH. Significance: ${ }^{\#} P<0.05$ versus DMSO, ${ }^{\# \# \# ~} P<0.001$ versus DMSO, ${ }^{*} P<0.05$ versus DMSO $+\mathrm{H}_{2} \mathrm{O}_{2}$, ${ }^{* *} P<0.01$ versus DMSO $+\mathrm{H}_{2} \mathrm{O}_{2},{ }^{* * *} P<0.001$ versus DMSO $+\mathrm{H}_{2} \mathrm{O}_{2}$, and ${ }^{\&} P<0.05$ versus DATS $+\mathrm{H}_{2} \mathrm{O}_{2}$.

associated with production of $\mathrm{H}_{2} \mathrm{~S}$ within cells. Our data elucidated, at least partially, the mechanisms underlying DATS's antifibrotic activity and indicated a therapeutic role of targeting $\mathrm{H}_{2} \mathrm{~S}$ for treatment of liver fibrosis.

\section{Competing Interests}

The authors declare that there is no conflict of interests regarding the publication of this paper.

\section{Acknowledgments}

This work was supported by the Natural Science Foundation of Jiangsu Province (BK20140955), the National Natural Science Foundation of China (31571455, 31401210, 31600653, 81600483, and 81270514), the Open Project Program of Jiangsu Key Laboratory for Pharmacology and Safety Evaluation of Chinese Materia Medica (JKLPSE201601 and 201502), and the Project of the Priority Academic Program Development of Jiangsu Higher Education Institutions (PAPD) and was also sponsored by the Qing Lan Project of Jiangsu Province.

\section{References}

[1] S. L. Friedman, "Evolving challenges in hepatic fibrosis," Nature Reviews. Gastroenterology \& Hepatology, vol. 7, no. 8, pp. 425436, 2010

[2] F. Tacke and R. Weiskirchen, "Update on hepatic stellate cells: pathogenic role in liver fibrosis and novel isolation techniques," Expert Review of Gastroenterology \& Hepatology, vol. 6, no. 1, pp. 67-80, 2012.

[3] V. Sánchez-Valle, N. C. Chávez-Tapia, M. Uribe, and N. Méndez-Sánchez, "Role of oxidative stress and molecular changes in liver fibrosis: a review," Current Medicinal Chemistry, vol. 19, no. 28, pp. 4850-4860, 2012.
[4] F. Zhang, C. Ni, D. Kong et al., "Ligustrazine attenuates oxidative stress-induced activation of hepatic stellate cells by interrupting platelet-derived growth factor- $\beta$ receptor-mediated ERK and p38 pathways," Toxicology and Applied Pharmacology, vol. 265, no. 1, pp. 51-60, 2012.

[5] M. S. Butt, M. T. Sultan, M. S. Butt, and J. Iqbal, "Garlic: nature's protection against physiological threats," Critical Reviews in Food Science and Nutrition, vol. 49, no. 6, pp. 538-551, 2009.

[6] T. Ariga and T. Seki, "Antithrombotic and anticancer effects of garlic-derived sulfur compounds: a review," BioFactors, vol. 26, no. 2, pp. 93-103, 2006.

[7] X. Zhu, F. Zhang, L. Zhou et al., "Diallyl trisulfide attenuates carbon tetrachloride-caused liver injury and fibrogenesis and reduces hepatic oxidative stress in rats," Naunyn-Schmiedeberg's Archives of Pharmacology, vol. 387, no. 5, pp. 445-455, 2014.

[8] S. Fiorucci, E. Distrutti, G. Cirino, and J. L. Wallace, "The emerging roles of hydrogen sulfide in the gastrointestinal tract and liver," Gastroenterology, vol. 131, no. 1, pp. 259-271, 2006.

[9] E. J. Norris, C. R. Culberson, S. Narasimhan, and M. G. Clemens, "The liver as a central regulator of hydrogen sulfide," Shock, vol. 36, no. 3, pp. 242-250, 2011.

[10] Y. Oya-Ohta, T. Ochi, Y. Komoda, and K. Yamamoto, “The biological activity of hydrogen peroxide. VI. Mechanism of the enhancing effects of 1-histidine: the role of the formation of a histidine-peroxide adduct and membrane transport," Mutation Research/Fundamental and Molecular Mechanisms of Mutagenesis, vol. 326, no. 1, pp. 99-107, 1995.

[11] G. A. Benavides, G. L. Squadrito, R. W. Mills et al., "Hydrogen sulfide mediates the vasoactivity of garlic," Proceedings of the National Academy of Sciences of the United States of America, vol. 104, no. 46, pp. 17977-17982, 2007.

[12] X. Zhang, F. Zhang, D. Kong et al., "Tetramethylpyrazine inhibits angiotensin II-induced activation of hepatic stellate cells associated with interference of platelet-derived growth factor $\beta$ receptor pathways," FEBS Journal, vol. 281, no. 12, pp. 2754-2768, 2014.

[13] G. D’Argenio, D. C. Amoruso, G. Mazzone et al., "Garlic extract prevents $\mathrm{CCl}_{4}$-induced liver fibrosis in rats: the role of tissue 
transglutaminase," Digestive and Liver Disease, vol. 42, no. 8, pp. 571-577, 2010.

[14] N. Gedik, L. Kabasakal, Ö. Şehirli et al., "Long-term administration of aqueous garlic extract (AGE) alleviates liver fibrosis and oxidative damage induced by biliary obstruction in rats," Life Sciences, vol. 76, no. 22, pp. 2593-2606, 2005.

[15] S. Mani, W. Cao, L. Wu, and R. Wang, "Hydrogen sulfide and the liver," Nitric Oxide, vol. 41, pp. 62-71, 2014.

[16] G. Tan, S. Pan, J. Li et al., "Hydrogen sulfide attenuates carbon tetrachloride-induced hepatotoxicity, liver cirrhosis and portal hypertension in rats," PLoS ONE, vol. 6, no. 10, Article ID e25943, 2011.

[17] H.-N. Fan, H.-J. Wang, L. Ren et al., "Decreased expression of p38 MAPK mediates protective effects of hydrogen sulfide on hepatic fibrosis," European Review for Medical and Pharmacological Sciences, vol. 17, no. 5, pp. 644-652, 2013.

[18] H. N. Fan, H. J. Wang, C. R. Yang-Dan et al., "Protective effects of hydrogen sulfide on oxidative stress and fibrosis in hepatic stellate cells," Molecular Medicine Reports, vol. 7, no. 1, pp. 247253, 2013.

[19] G. Yang, L. Wu, and R. Wang, "Pro-apoptotic effect of endogenous $\mathrm{H}_{2} \mathrm{~S}$ on human aorta smooth muscle cells," The FASEB Journal, vol. 20, no. 3, pp. 553-555, 2006.

[20] C. Wang, J. Han, L. Xiao, C.-E. Jin, D.-J. Li, and Z. Yang, "Role of hydrogen sulfide in portal hypertension and esophagogastric junction vascular disease," World Journal of Gastroenterology, vol. 20, no. 4, pp. 1079-1087, 2014.

[21] K. Kang, M. Zhao, H. Jiang, G. Tan, S. Pan, and X. Sun, "Role of hydrogen sulfide in hepatic ischemia-reperfusion-induced injury in rats," Liver Transplantation, vol. 15, no. 10, pp. 13061314, 2009.

[22] K.-C. Lai, S.-C. Hsu, J.-S. Yang, C.-C. Yu, J.-C. Lein, and J.G. Chung, "Diallyl trisulfide inhibits migration, invasion and angiogenesis of human colon cancer HT-29 cells and umbilical vein endothelial cells, and suppresses murine xenograft tumour growth," Journal of Cellular and Molecular Medicine, vol. 19, no. 2, pp. 474-484, 2015.

[23] K. Chandra-Kuntal, J. Lee, and S. V. Singh, "Critical role for reactive oxygen species in apoptosis induction and cell migration inhibition by diallyl trisulfide, a cancer chemopreventive component of garlic," Breast Cancer Research and Treatment, vol. 138, no. 1, pp. 69-79, 2013.

[24] R. Weiskirchen and F. Tacke, "Cellular and molecular functions of hepatic stellate cells in inflammatory responses and liver immunology," Hepatobiliary Surgery and Nutrition, vol. 3, no. 6, pp. 344-363, 2014.

[25] M. Whiteman, L. Li, P. Rose, C.-H. Tan, D. B. Parkinson, and P. K. Moore, "The effect of hydrogen sulfide donors on lipopolysaccharide-induced formation of inflammatory mediators in macrophages," Antioxidants and Redox Signaling, vol. 12, no. 10, pp. 1147-1154, 2010.

[26] Y. Kimura, Y.-I. Goto, and H. Kimura, "Hydrogen sulfide increases glutathione production and suppresses oxidative stress in mitochondria," Antioxidants \& Redox Signaling, vol. 12, no. 1, pp. 1-13, 2010.

[27] S. Jha, J. W. Calvert, M. R. Duranski, A. Ramachandran, and D. J. Lefer, "Hydrogen sulfide attenuates hepatic ischemiareperfusion injury: role of antioxidant and antiapoptotic signaling," American Journal of Physiology - Heart and Circulatory Physiology, vol. 295, no. 2, pp. H801-H806, 2008.

[28] N. N. Osborne, D. Ji, A. S. A. Majid, R. J. Fawcett, A. Sparatore, and P. Del Soldato, "ACS67, a hydrogen sulfide-releasing derivative of latanoprost acid, attenuates retinal ischemia and oxidative stress to RGC-5 cells in culture," Investigative Ophthalmology and Visual Science, vol. 51, no. 1, pp. 284-294, 2010. 


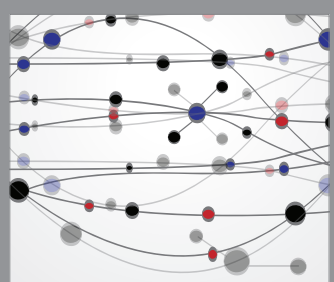

The Scientific World Journal
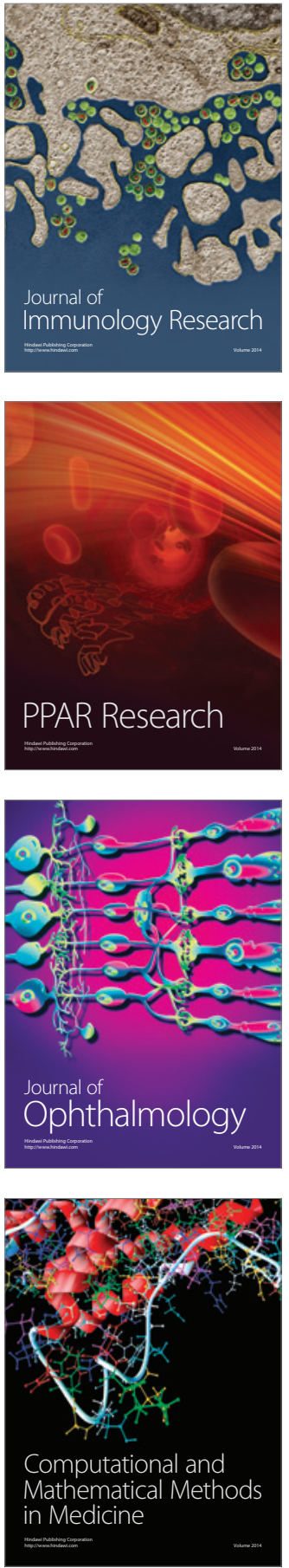

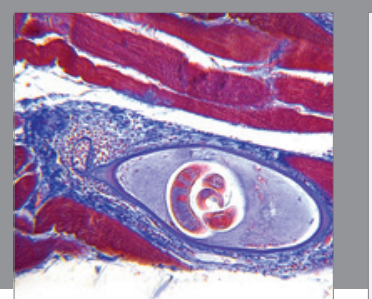

Gastroenterology Research and Practice
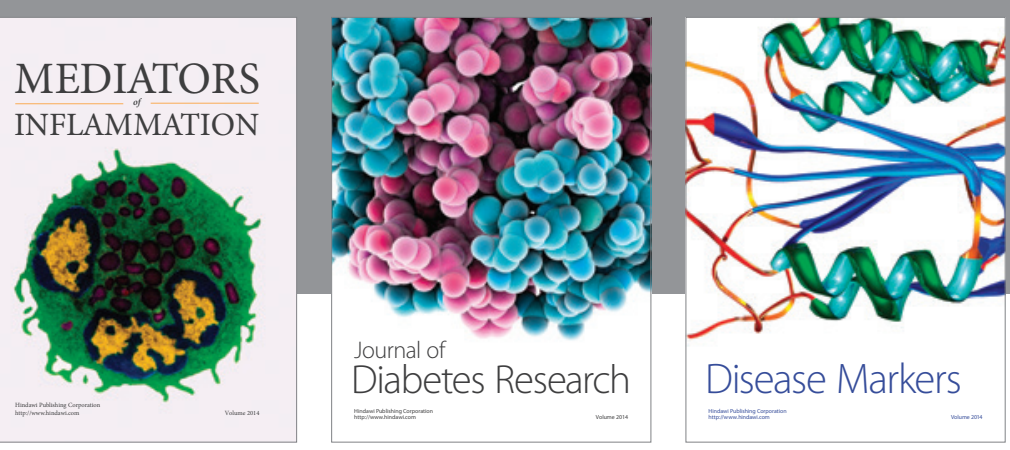

Disease Markers

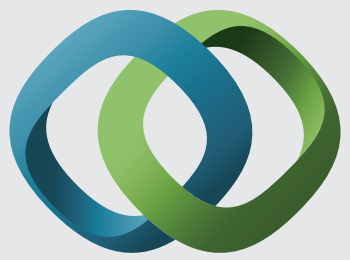

\section{Hindawi}

Submit your manuscripts at

https://www.hindawi.com
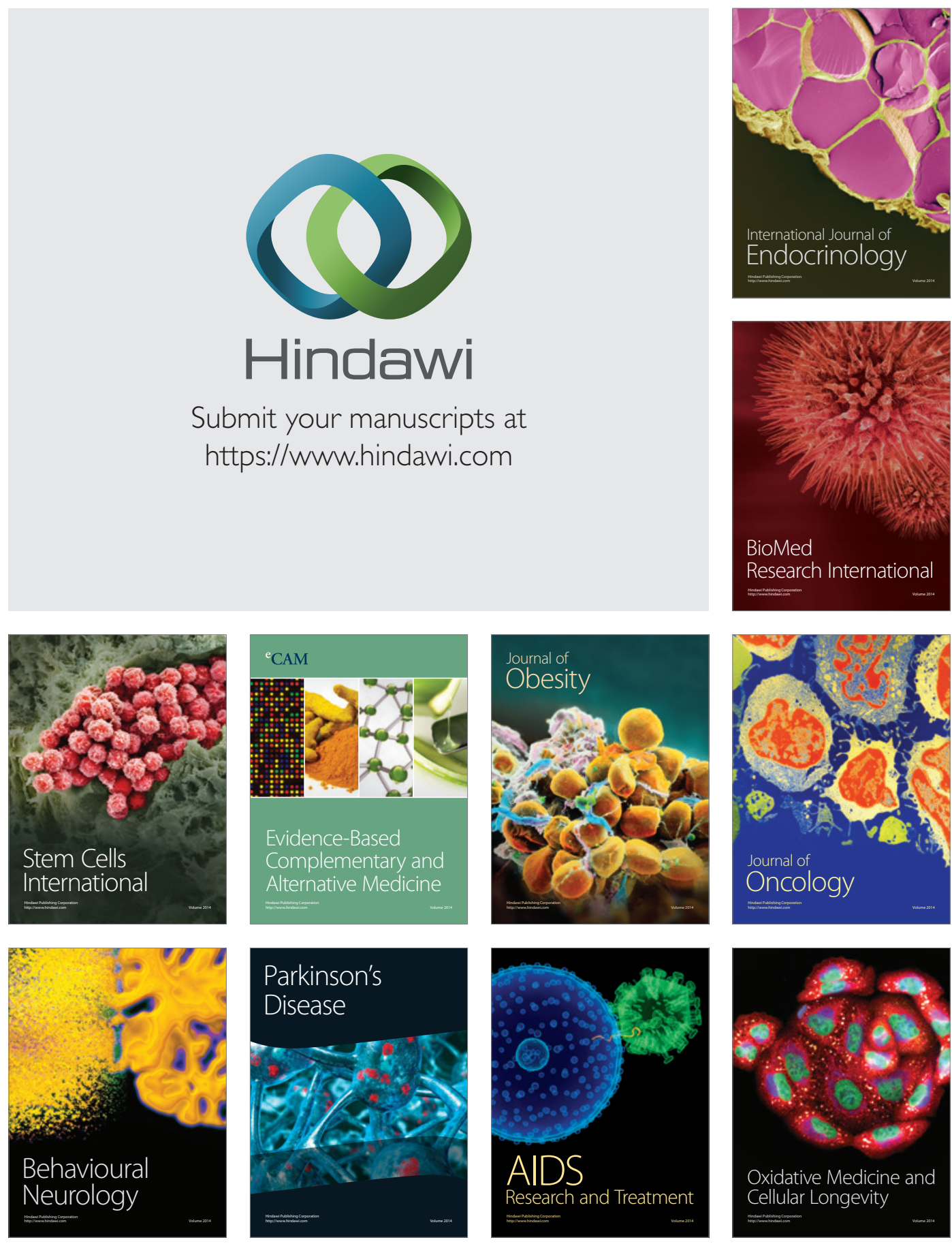